\title{
Rapid detection of immunoglobulin heavy chain gene rearrangement by PCR and melting curve analysis using combined FR2 and FR3 primers
}

Danfei Xu', Zhuo Yang ${ }^{1}$, Donghong Zhang ${ }^{1}$, Wei Wu' ${ }^{1}$ Ye Guo ${ }^{1}$, Qian Chen ${ }^{1}$, Dongsheng $X u^{2}$ and Wei Cui ${ }^{*}$

\begin{abstract}
Background: Immunoglobulin heavy chain $(\mathrm{lgH})$ gene rearrangement test is a standard tool in diagnosing B-cell lymphoma. The BIOMED-2 multiplex PCR protocol has become the most commonly used laboratory method for detecting clonal lgH gene rearrangement. However, post-PCR procedure requires manual transfer of PCR product for analysis and is time-consuming. A novel strategy using LightCycler to continuously monitor fluorescence during melting curve analysis (MCA) can overcome these shortcomings. The previous studies published on this method were all restricted to FR3 primers of BIOMED-2.
\end{abstract}

Methods: Real-time PCR and subsequent MCA were performed on 71 clinical DNA samples from formalin-fixed, paraffin-embedded tissues, including 40 with B-cell non-Hodgkin lymphomas and 31 with reactive lymphoid hyperplasia. We optimized the current method using FR3 primers and applied FR2 primers for the first time into MCA to detect IgH gene rearrangement. Polyacrylamide gel electrophoresis and capillary gel electrophoresis were also performed on all lymphoma samples with the identical FR2 primers.

Results: MCA of combined FR2 and FR3 primer sets yielded the sensitivity and the specificity equal to $70 \%(28 / 40)$ and $100 \%$ (31/31), respectively. Addition of FR2 primers increased the sensitivity by $12.5 \%(5 / 40)$ comparing to FR3 primers alone. MCA was slightly more sensitive than polyacrylamide gel electrophoresis and comparable to capillary gel electrophoresis to detect clonal lgH gene rearrangement.

Conclusions: Combined PCR and DNA melting curve analysis in a closed system can reduce cross-contamination risk. This method can test 96 samples simultaneously within 90 min and therefore, it is high-throughput and faster. PCR-MCA in the LightCycler system has potential for evaluating monoclonal lgH gene rearrangement in a clinical environment.

\section{Background}

Non-Hodgkin B-cell lymphoma accounts for a significant proportion of malignant lymphomas [1-3]. Despite well-established diagnostic criteria, such as morphology and immunophenotyping, the clonality testing by immunoglobulin heavy chain (IgH) gene rearrangement is required in approximately $10 \%$ of cases [4]. The IgH gene contains many different variable $(\mathrm{V})$, diversity $(\mathrm{D})$, and joining $(J)$ segments, which are subject to randomly

\footnotetext{
* Correspondence: cuiw@pumch.cn

'Department of Clinical Laboratory, Peking Union Medical College Hospital, Peking Union Medical College, Chinese Academy of Medical Sciences, Beijing 100730, China

Full list of author information is available at the end of the article
}

rearranged processes during early B-cell development, creating a unique hallmark for each B-cell [5]. V segments contain three framework regions (FRs) and two complementarity determining regions (CDRs). Unlike the FRs that are similar among various $\mathrm{V}$ segments, the CDRs are highly variable even within the same $\mathrm{V}$ family [6]. Since B-cell malignancies contain identically rearranged IgH genes, PCR priming at FRs is able to detect monoclonal B-cell population in the form of single band on gel or sharp peak on fragment analyser [7-9]. Of many DNA-based PCR tests, the protocol developed as a result of BIOMED-2 collaborative study [6] using three sets of primers named FR1, FR2 and FR3 has become the most commonly used laboratory method. 
Current DNA-based PCR methods for detecting monoclonal IgH gene rearrangement (IgH-R) include polyacrylamide gel electrophoresis (PAGE), capillary gel electrophoresis (CE) or denaturing gradient gel electrophoresis [7-10]. These methods consist primarily of two separate steps: PCR amplification and post-PCR amplicon analysis. Xu et al. [11] developed a novel PCR method for detecting clonal IgH-R that continuously monitored fluorescence of the specific double-stranded DNA binding dye SYBR green I during melting curve analysis (MCA) on LightCycler. This method that used the FR3 primer set of BIOMED-2 was faster and reliable, and combined PCR and DNA MCA in a closed system reduced post-PCR crosscontamination risk. In this report, we reinvestigate PCR with FR3 primers and MCA strategy using the newest modal of LightCycler (Roche LightCycler 480 II). We have improved the analytical sensitivity using FR3 primers. In addition, we include FR2 primers for the first time into the protocol, and demonstrate that PCR in LightCycler system with melting curve analysis using combined FR2 and FR3 primers can increase the detection sensitivity, and is a reliable and reproducible method to diagnose the monoclonal IgH gene rearrangements.

\section{Methods}

\section{Patient samples}

Total 71 formalin-fixed paraffin-embedded (FFPE) tissue samples were collected during 2012 to 2014 at Peking Union Medical College Hospital. Fourty were from patients with B-cell non-Hodgkin lymphoma (B$\mathrm{NHL}$ ), and 31 were from patients with reactive lymphoid hyperplasia. All cases were definitively diagnosed by the pathologists and hematologists according to the World Health Organization system for the classification of hematolymphoid neoplasms. A mixture of 17 DNA samples from reactive lymphoid hyperplasia and Ramos DNA were used as negative and positive controls, respectively.

\section{DNA extraction}

A microscopic examination was first made on a $5-\mu \mathrm{m}$ thick H\&E section to confirm the presence of suspected tumor cells of at least $80 \%$. Then, five $5-\mu \mathrm{m}$ thick sections were consecutively cut and placed in a $1.5 \mathrm{ml}$ tube. DNA was extracted according to the instructions from the TIANamp FFPE DNA kit (Tiangen, Beijing, China). The concentration of DNA was measured by NanoDrop (Thermo Fisher Scientific, Shanghai, China). The quality of each DNA sample was evaluated by amplifying a 333-bp fragment of the immunoglobulin $\mathrm{M}(\mathrm{C} \mu)$.

\section{PCR primers}

Two sets of primers referring to BIOMED-2 design [6] were synthesized by Invitrogen Biotechnology including
IgH variable framework region 2 (FR2) and framework region 3 (FR3) plus joining region (JH). The primers for $\mathrm{C} \mu$ were designed by Primer-BLAST that amplified a constant region of immunoglobulin $\mu$ chain. The sequences were as followings:

\section{C $\mu$-F: 5'-GGCAAGGCCAAGAACTGTCT-3'; C $\mu$-R: 5'-TACATGGGCATCTCAAGGGG-3'.}

\section{LightCycler multiplex PCR and melting curve analysis (MCA)}

DNA from each sample was amplified in the LightCycler 480 II (Roche Diagnostic, Shanghai, China) by three primer sets, FR2, FR3 and $\mathrm{C} \mu$, in three independent tubes. The reaction mixture of each well contained $\mathrm{SYBR}^{\circ}$ Premix Ex Taq ${ }^{\mathrm{Tm}}$ II master (Takara BIO, Dalian, China) $10 \mu \mathrm{l}, 10 \mu \mathrm{mol} / \mathrm{l}$ of each primer $0.4 \mu \mathrm{l}$, genomic DNA $100 \mathrm{ng}$, and $\mathrm{dH}_{2} \mathrm{O}$ PCR grade with a final volume of $20 \mu \mathrm{l}$ [12]. The PCR conditions were the same for all primer sets as followings: $95{ }^{\circ} \mathrm{C} 15 \mathrm{~s}, 62{ }^{\circ} \mathrm{C} 15 \mathrm{~s}$ and $72{ }^{\circ} \mathrm{C} 20 \mathrm{~s}$. After 40 amplification cycles, MCA was performed. Briefly, PCR products were denatured at $95{ }^{\circ} \mathrm{C}$ for $1 \mathrm{~min}$, annealed at $62{ }^{\circ} \mathrm{C}$ for $15 \mathrm{~s}$ and quickly raised to $75^{\circ} \mathrm{C}$, the temperature was then raised slowly from $75{ }^{\circ} \mathrm{C}$ to $93{ }^{\circ} \mathrm{C}$ at a transition rate of $0.05{ }^{\circ} \mathrm{C} / \mathrm{s}$ during continuous fluorescence monitoring at $521 \mathrm{~nm}$. Results were analysed by the Tm Calling software (Roche Diagnostic).

\section{Gel detection - PAGE (Heteroduplex analysis)}

The IgH Tube B Master Mixture (InVivoScribe Technologies) that contains identical FR2 primer set was used to amplify the IgH gene variable region in a thermal cycler (BIO-RAD, Berkeley, CA, USA). 100 ng of genomic DNA was added up to a final reaction volume of $50 \mu \mathrm{l}$. After an initial "hot start" using AmpliTaq Gold (Applied Biosystems) at $95{ }^{\circ} \mathrm{C}$ for $7 \mathrm{~min}$, the PCR cycle parameters were set as followings: denaturing at $95{ }^{\circ} \mathrm{C}$ for $45 \mathrm{~s}$, followed by annealing at $60{ }^{\circ} \mathrm{C}$ for $45 \mathrm{~s}$, and extending at $72{ }^{\circ} \mathrm{C}$ for $90 \mathrm{~s}$. This program was repeated for 35 cycles. A final extension was performed at $72{ }^{\circ} \mathrm{C}$ for $10 \mathrm{~min}$. For PAGE analysis, $10 \mu \mathrm{l}$ of PCR products were denatured at $94{ }^{\circ} \mathrm{C}$ for $5 \mathrm{~min}$ and quickly chilled at $4{ }^{\circ} \mathrm{C}$ for $60 \mathrm{~min}$. Each sample was mixed with $2 \mu \mathrm{l}$ of $5 \mathrm{x}$ loading buffer before added on a $6 \%$ non-denaturing acrylamide gel. The gel was run at room temperature for $50 \mathrm{~min}$ at 120 volts, stained with $0.5 \%$ of GelRed (Fanbo Biochemicals, Beijing, China) and then visualized using UV illuminator (BIO-RAD, USA). The expected size range of the amplicons varied from 250 to $295 \mathrm{bp}$.

\section{Capillary gel electrophoresis (CE)}

Premix Ex Taq master (Takara BIO, Dalian, China) and hexachloro (HEX) fluorescence labelled FR2 primers were used. PCR reaction system and condition were the same as 


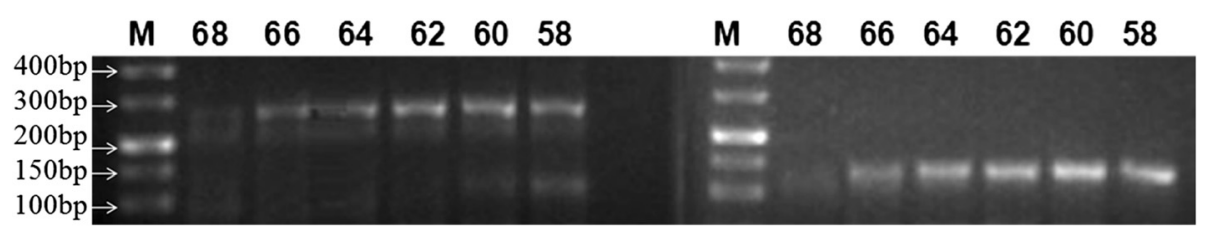

Fig. 1 Annealing temperature gradient PCR on Ramos cell line. FR2 (left) and FR3 (right) primers were used to amplify Ramos cell line DNA with gradient annealing temperature from $58{ }^{\circ} \mathrm{C}$ to $68{ }^{\circ} \mathrm{C}$ to explore the optimal annealing temperature for both multiplex-PCR sets

those mentioned in the section of LightCycler multiplex PCR and MCA. The amplified fragments were analysed by ABI 3130 Genetic Analyzer (Applied Biosystems). Briefly, $1 \mu \mathrm{l}$ of the PCR product was transferred to $10 \mu \mathrm{l}$ of $\mathrm{Hi}-\mathrm{Di}$ formamide with ROX size standards (InVivoScribe technology). Samples were denatured at $95{ }^{\circ} \mathrm{C}$ for $5 \mathrm{~min}$, immediately chilled on ice for $2 \mathrm{~min}$ and analysed by the Peak Scanner software (Life Technology). The expected sizes varied from 250 to $295 \mathrm{bp}$.

\section{Results}

Establishment of LightCycler multiplex PCR and MCA

An annealing temperature gradient PCR on Ramos (Human B-cell non-Hodgkin lymphoma cell line) DNA from $58{ }^{\circ} \mathrm{C}$ to $68{ }^{\circ} \mathrm{C}$ was run to determine the optimal annealing temperature for multiplex PCR. According to the agarose gel electrophoresis results, the annealing temperature of $62{ }^{\circ} \mathrm{C}$ was suitable for both FR2 and FR3 primers (Fig. 1). Based on the previous studies [9, 10], 40 cycles of LightCycler PCR were sufficient for DNA amplification. Therefore, $62{ }^{\circ} \mathrm{C}$ and 40 cycles were used in this study. The 17 reactive lymphoid hyperplasia samples were individually tested by MCA. The result showed that all reactive samples as well as the negative control had flat, wide, irregular peaks with $-\mathrm{dF} / \mathrm{dT}$ values less than 3.5 for FR2 or less than 2.5 for FR3. On the other hand, the positive control yielded a single sharp peak with a distinct Tm (Fig. 2). Therefore, the criteria for diagnosing a monoclonal $\operatorname{IgH}$ gene rearrangement were established as having a single sharp peak with the $-\mathrm{dF} / \mathrm{dT}$ value equal to or greater than 3.5 for FR2 and 2.5 for FR3, respectively.

\section{Capability of distinguishing lymphoma in clinical FFPE samples}

A total of 71 FFPE samples were analysed by PCRMCA. All 31 lymphoid hyperplasia samples had -dF/dT values $<3.5$ for FR2 and $<2.5$ for FR3, resulting in the specificity of $100 \%$. Among 40 lymphoma samples, 28 (70.0 \%) samples were positive for monoclonal IgH gene rearrangement (Table 1) including 5 with FR2 rearranged, 5 with FR3 rearranged, and 18 with both FR2 and FR3 rearranged. Therefore, inclusion of FR2 primers increased the sensitivity by $12.5 \%(5 / 40)$ comparing to use the FR3
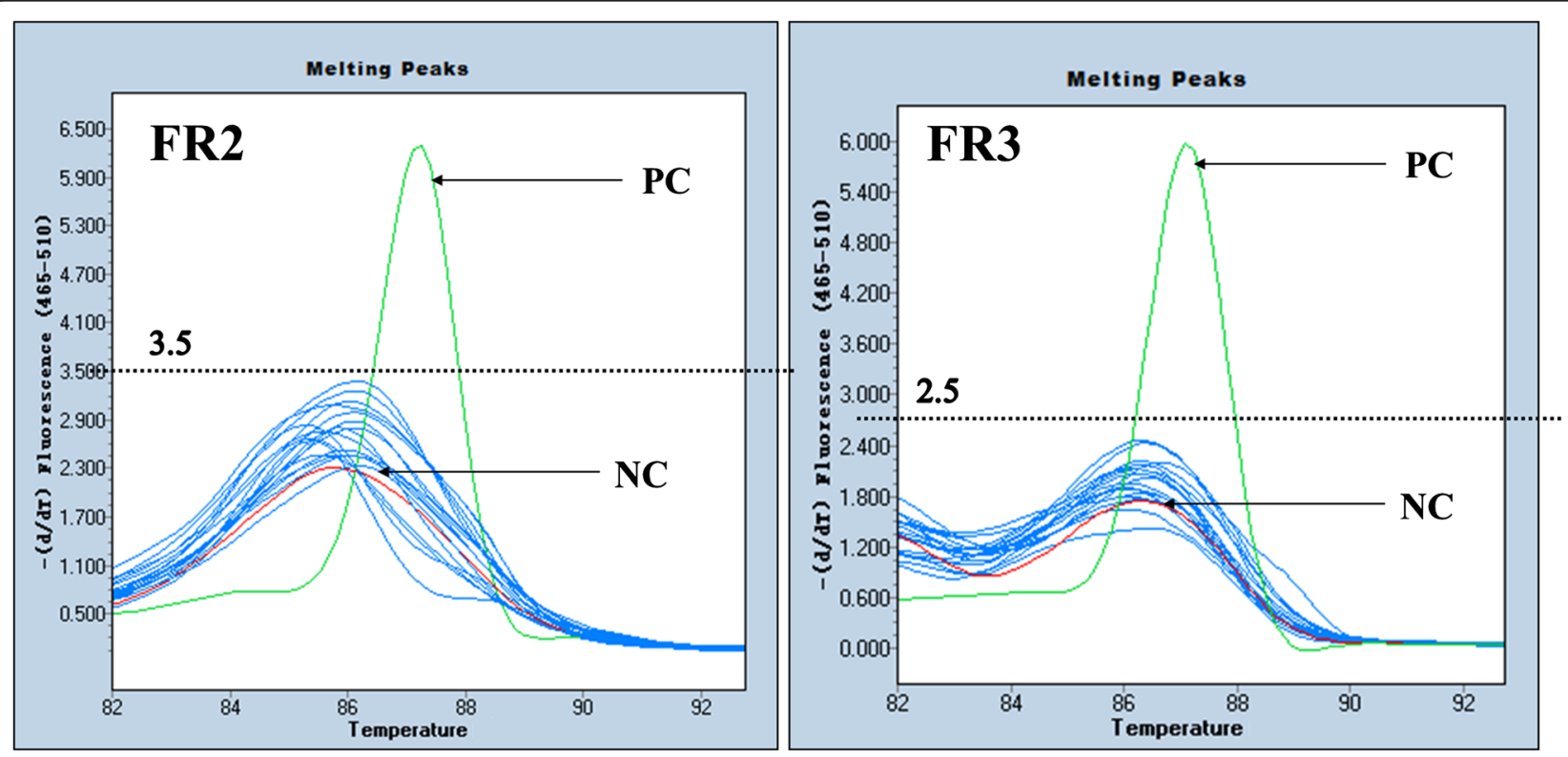

Fig. 2 Melting curve analysis of 17 lymphoid hyperplasia samples. NC: negative control (red line); PC: positive control (green line); $X$ axis = temperature $\left({ }^{\circ} \mathrm{C}\right)$; $\mathrm{Y}$ axis $=-\mathrm{dF} / \mathrm{dT}$, where $\mathrm{F}=$ fluorescence and $\mathrm{T}=$ temperature 
Table 1 Summary of clinical lymphoma samples analysed by MCA, PAGE and CE

\begin{tabular}{|c|c|c|c|c|c|c|c|}
\hline Patient & Age/sex & Diagnosis & Tissue & MCA-FR3 $\left(\operatorname{Tm}^{\circ} \mathrm{C}\right)$ & MCA-FR2 $\left(\mathrm{Tm}^{\circ} \mathrm{C}\right)$ & PAGE-FR2 & CE-FR2(nt) \\
\hline 1 & $39 / F$ & SLL & Inguinal LN & $P(84.78)$ & $P(86.34)$ & $P$ & $P(295)$ \\
\hline 2 & $53 / F$ & $\mathrm{MCL}$ & Intestine & $P(86.17)$ & $P(86.83)$ & $P$ & $P(251)$ \\
\hline 3 & $54 / F$ & CLL/SLL & Lung & $P(85.44)$ & $N$ & $N$ & $\mathrm{~N}$ \\
\hline 4 & $61 / F$ & $M C L$ & Neck Skin & $P(87.95)$ & $P(87.68)$ & $P$ & $P(254)$ \\
\hline 5 & $54 / F$ & CLL/SLL & Tonsil & $P(86.94)$ & $P(87.18)$ & $P$ & $P(253)$ \\
\hline 6 & $61 / F$ & MZL & Spleen & $P(84.93)$ & $P(87.03)$ & $P$ & $P(285)$ \\
\hline 7 & $51 / F$ & DLBCL & Lung & $P(84.89)$ & $P(85.20)$ & $P$ & $P(286)$ \\
\hline 8 & $47 / F$ & B-NHL-UC & Brain & $P(85.72)$ & $N$ & $N$ & $N$ \\
\hline 9 & $63 / \mathrm{M}$ & MZL & Neck Skin & $P(86.17)$ & $P(86.96)$ & $P$ & $P(277)$ \\
\hline 10 & $49 / M$ & MZL & Parotid Gland & $P(88.54)$ & N & $N$ & $N$ \\
\hline 11 & $66 / F$ & CLL/SLL & Inguinal LN & $P(86.80)$ & $P(86.48)$ & $P$ & $P(260)$ \\
\hline 12 & $77 / F$ & B-NHL-UC & Eyelid & $P(86.52)$ & $P(85.60)$ & $P$ & $P(254)$ \\
\hline 13 & $75 / F$ & B-NHL-UC & Tongue & $P(84.83)$ & $P(85.50)$ & $P$ & $P(280)$ \\
\hline 14 & $27 / M$ & MZL & Parotid Gland & $P(85.80)$ & $P(86.64)$ & $P$ & $P(273)$ \\
\hline 15 & $43 / \mathrm{M}$ & MZL & Lung & $P(84.88)$ & $P(86.69)$ & $P$ & $P(265)$ \\
\hline 16 & $56 / \mathrm{M}$ & DLBCL & Spleen & $N$ & N & $N$ & N \\
\hline 17 & $65 / F$ & B-NHL-UC & Spleen & $P(85.67)$ & $N$ & $N$ & $N$ \\
\hline 18 & $68 / \mathrm{M}$ & B-NHL-UC & Inguinal LN & N & $P(87.14)$ & $P$ & $P(265)$ \\
\hline 19 & $51 / F$ & $\mathrm{FL}$ & Neck Skin & $P(87.77)$ & $P(87.64)$ & $P$ & $P(259)$ \\
\hline 20 & $40 / F$ & DLBCL & Ovary & $N$ & $N$ & $N$ & N \\
\hline 21 & $74 / \mathrm{M}$ & $\mathrm{MCL}$ & Tonsil & $P(84.21)$ & $P(85.14)$ & $P$ & $P(277)$ \\
\hline 22 & $28 / F$ & $\mathrm{FL}$ & Axillary LN & $\mathrm{N}$ & $N$ & $N$ & $N$ \\
\hline 23 & $50 / \mathrm{M}$ & DLBCL & Nasopharyngeal LN & $N$ & $N$ & $N$ & $N$ \\
\hline 24 & $61 / F$ & MZL & Spleen & $P(83.10)$ & $P(87.16)$ & $P$ & $P(272)$ \\
\hline 25 & $75 / F$ & DLBCL & Pelvic Tumor & $P(86.52)$ & $P(86.14)$ & UD & $P(272)$ \\
\hline 26 & $44 / \mathrm{M}$ & B-NHL-UC & Axillary LN & $P(87.45)$ & $P(87.35)$ & UD & $P(272)$ \\
\hline 27 & $73 / F$ & MZL & Mandibular Gland & $N$ & $P(85.08)$ & $P$ & $P(259)$ \\
\hline 28 & $68 / F$ & DLBCL & Colon & $N$ & $N$ & $N$ & $N$ \\
\hline 29 & $63 / F$ & DLBCL & Axillary LN & $P(86.96)$ & $N$ & $N$ & $P(254 / 263)$ \\
\hline 30 & $62 / M$ & $\mathrm{FL}$ & Colon & $N$ & $N$ & $N$ & $N$ \\
\hline 31 & $70 / F$ & MZL & Stomach & $N$ & $N$ & $N$ & $N$ \\
\hline 32 & $72 / \mathrm{M}$ & DLBCL & Pectoral LN & $N$ & $N$ & $N$ & $N$ \\
\hline 33 & $77 / F$ & DLBCL & Cheek Skin & $\mathrm{N}$ & $\mathrm{N}$ & $N$ & $N$ \\
\hline 34 & $62 / M$ & DLBCL & Spleen & $N$ & $P(86.25)$ & $P$ & $P(259)$ \\
\hline 35 & $79 / F$ & DLBCL & Tonsil & $\mathrm{N}$ & N & N & N \\
\hline 36 & $58 / \mathrm{M}$ & DLBCL & Lung & $N$ & $P(85.18)$ & $P$ & $P(242)$ \\
\hline 37 & $65 / F$ & MZL & Thyroid & $\mathrm{N}$ & $\mathrm{N}$ & $N$ & $\mathrm{~N}$ \\
\hline 38 & $38 / \mathrm{M}$ & MZL & Conjunctiva & $N$ & $P(84.45)$ & $P$ & $P(262)$ \\
\hline 39 & $62 / M$ & DLBCL & Neck Skin & $P(86.82)$ & $P(86.30)$ & P & $P(248)$ \\
\hline 40 & $62 / F$ & DLBCL & Stomach & $\mathrm{N}$ & $N$ & $\mathrm{~N}$ & $\mathrm{~N}$ \\
\hline
\end{tabular}

The Tms of clonal samples tested by MCA and segment length from CE are listed in the parentheses

CLL/SLL chronic lymphocytic leukemia/small lymphocytic lymphoma, DLBCL diffuse large B-cell lymphoma, FL follicular lymphoma, MCL mantle cell lymphoma, MZL marginal zone B-cell lymphoma, B-NHL-UC unclassified B-NHL, $L N$ Lymph node, $P$ positive, $N$ negative, UD undetermined 
primers alone. The Tms of 23 FR2 monoclonal clinical samples plus Ramos cell line ranged from $84{ }^{\circ} \mathrm{C}$ to $88{ }^{\circ} \mathrm{C}$ with the mean of $86.4{ }^{\circ} \mathrm{C}$ and the Tms of 23 FR3 monoclonal clinical samples plus Ramos cell line ranged from $83{ }^{\circ} \mathrm{C}$ to $89{ }^{\circ} \mathrm{C}$ with the mean of $86.1{ }^{\circ} \mathrm{C}$ (Table 1 ).

\section{Comparison of MCA with PAGE and CE}

Conventional BIOMED-2 protocol (PAGE) versus MCA for detecting monoclonal IgH gene rearrangement was compared in 40 clinical B-NHL samples. All negative cases by MCA were also negative by PAGE. For 23 FR2-positive cases detected by MCA, PAGE clearly detected 21 positive cases. The cases $25 \#$ and $26 \#$ showed very faint band respectively on PAGE at expected range (Fig. 3b). We interpreted the results as undetermined that need to be further confirmed. Melting curve analysis of internal control $\mathrm{C} \mu$ showed that these two samples had a specific peak (Fig. 3c). The fragments analysis by Peak Scanner showed the PCR products of the two samples have a monoclonal peak with designated sizes (Fig. 3d), consistent with MCA results. Of all 40 clinical B-NHL samples, CE detected 24 positive cases with FR2 primers. One showed biallelic rearrangement in $\mathrm{CE}$, but neither $\mathrm{MCA}$ nor PAGE demonstrated a positive result (Table 1). To further study the capability of MCA in distinguishing biallelic or bi-cloanl rearrangements with FR2 primers, equal amounts of two different clonal DNA samples
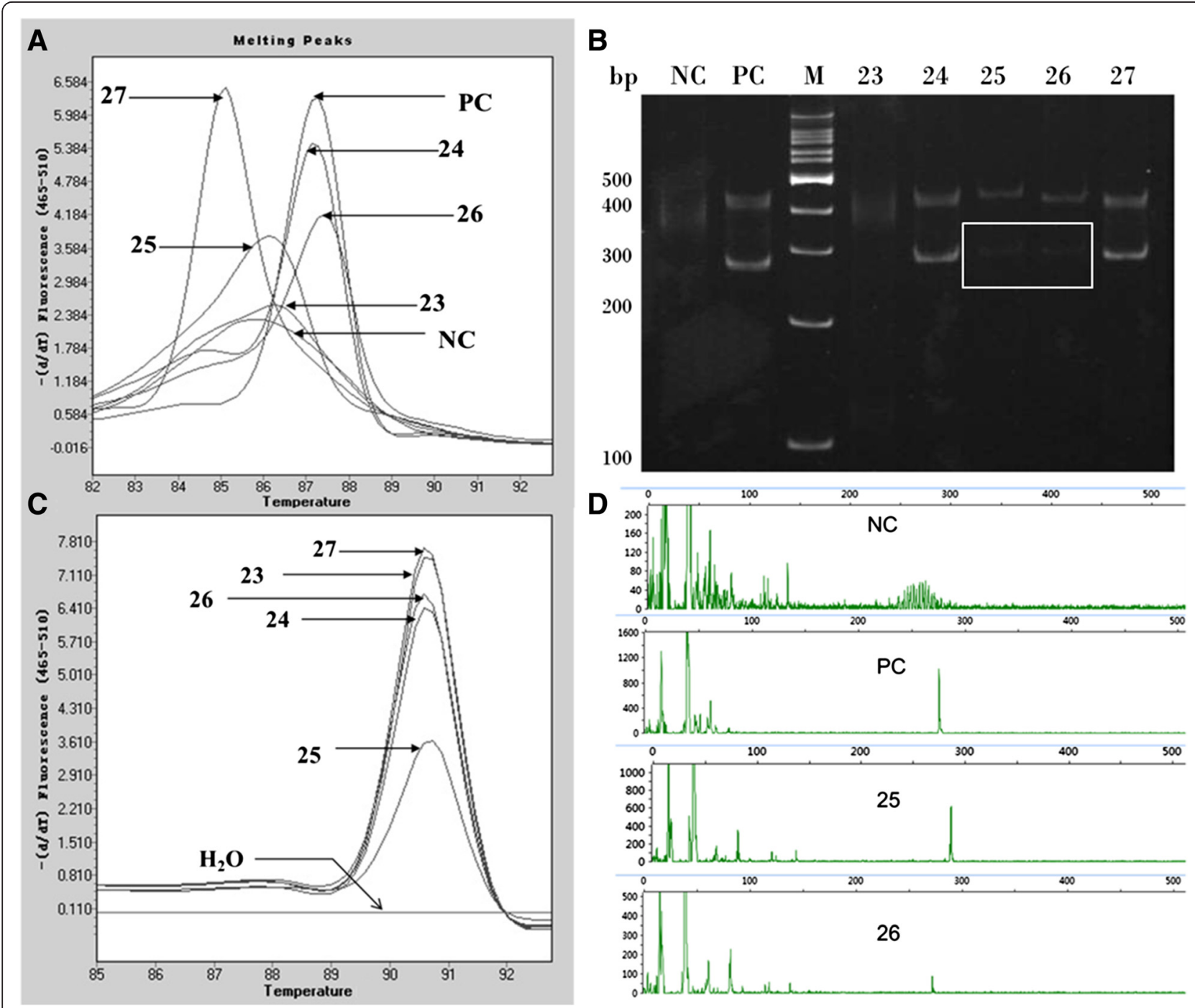

Fig. 3 Comparison of PAGE, MCA and CE. a MCA of 5 lymphoma samples with FR2 primers. Sample 23 was negative, 24-27 were positive. b PAGE of the same 5 lymphoma samples. A very faint band can hardly be seen in sample 25\# and 26\# (in box) that is interpreted as undetermined and need to be further confirmed. c Evaluation of DNA quality. All samples including 25\# and 26\# have a sharp peak at identical Tm, which indicated the presence of lymphoid tissue with integrated DNA. d CE of the sample 25\# and 26\#. Both samples had a single peak at expected sizes 
were mixed together, PCR-amplified with FR2 primer set and analysed using melting curve analysis (see below).

\section{Minimal detection of MCA}

To determine the minimal detection of IgH gene rearrangement with MCA, serial dilutions of Ramos cell line with the negative control at various percentages of $50 \%, 25 \%, 12.5 \%, 6.25 \%, 3.125 \%, 1.56 \%$ and $0.78 \%$ were prepared. After 40 cycles of amplification, we could still detect a single sharp peak at $3.125 \%$ with $-\mathrm{dF} / \mathrm{dT}$ values greater than 3.5 for FR2 and 2.5 for FR3, respectively on melting curve analysis (Fig. 4).

\section{Reproducibility of MCA}

Three consecutive melting curve analyses of DNA from Ramos cell line and FR2 positive clinical DNA samples yielded identical $-\mathrm{dF} / \mathrm{dT}$ versus $\mathrm{T}$ curves. The average Tm SD of all clonal DNA samples was 0.048. On the other hand, three consecutive melting curve analyses of DNA samples from reactive lymphoid hyperplasia produced different $-\mathrm{dF} / \mathrm{dT}$ versus T curves each time with an average Tm SD of 0.428. Therefore, we recommend performing three consecutive MCAs after DNA amplification to exclude the pseudoclonal high peak rarely observed with reactive lymphoid hyperplasia reported previously [13].

\section{Resolution of MCA using FR2 primers}

To test whether MCA could distinguish biallelic of biclonal rearrangements, equal amounts of clonal DNA samples with two different Tms were mixed, PCRamplified with FR2 primers and analysed using melting curve analysis (Table 2). We were not able to separate two clonal B-cell populations with $\triangle \mathrm{Tm}$ less than 1.05 (Experiments 1 and 2). However, we were able to distinguish two clonal B-cell populations with $\Delta \mathrm{Tm}$ equal to or greater than $2.03{ }^{\circ} \mathrm{C}$ (Table 2, experiments 3-5).

\section{Discussion}

The melting temperature (Tm) of double stranded DNA reflects fundamental physical properties that depend on length, sequence, G: C content and Watson-Crick base pairing [14-16]. Xu et al. [11] originally demonstrated that melting curve analysis based on internal melting domain found in CDRs can distinguish monoclonal from polyclonal IgH gene rearrangements. The PCR products from monoclonal B-cell population will present a single, sharp and symmetric peak at certain Tm on MCA, while those amplicons from polyclonal B-cell population will show flat, wide and irregular peaks. Xu et al. [11] showed that PCR-MCA yielded $100 \%$ of sensitivity (24/24) compared to PAGE and $58.3 \%$ of sensitivity (7/12) compared to southern blot analysis. Since then, several studies using PCR-MCA strategy to detect monoclonal IgH rearrangement have been reported [17-19]. Dobbs et al. [17] used an iCycler instrument and achieved $88.9 \%$ sensitivity, compared to PAGE. Retamales et al. [19] reported a $95.2 \%$ of sensitivity compared to PAGE, and concluded that PCR-MCA could distinguish reliably between monoclonal versus polyclonal IgH rearrangement in gastric lymphoid infiltrates. Compared to

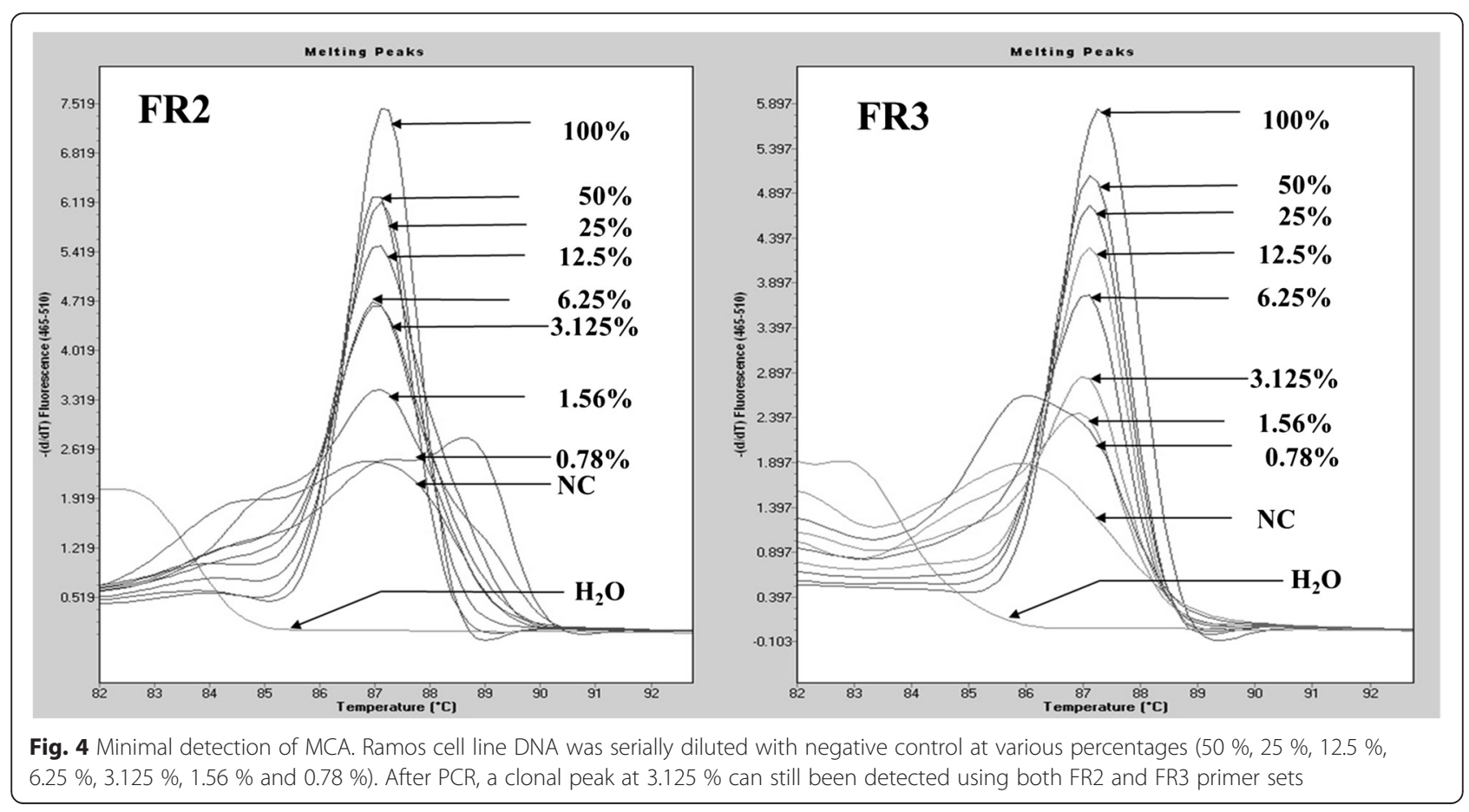


Table 2 MCA of two different clonal DNA samples using FR2 primers

\begin{tabular}{|c|c|c|c|c|c|}
\hline \multirow{2}{*}{$\begin{array}{l}\text { Experiment } \\
\text { NO. }\end{array}$} & \multicolumn{3}{|c|}{ Original } & \multicolumn{2}{|c|}{ After mixing } \\
\hline & $\mathrm{Tm} 1$ & Tm2 & $\Delta \mathrm{Tm}$ & Tml & $\operatorname{Tm} 2$ \\
\hline 1 & 84.45 & 85.18 & 0.73 & 84.45 & - \\
\hline 2 & 84.45 & 85.50 & 1.05 & 84.62 & - \\
\hline 3 & 84.45 & 88.48 & 2.03 & 84.41 & 86.56 \\
\hline 4 & 84.45 & 87.35 & 2.90 & 84.11 & 86.99 \\
\hline 5 & 84.45 & 87.68 & 3.23 & 84.23 & 87.50 \\
\hline
\end{tabular}

$\triangle \mathrm{Tm}$ : Difference of melting temperatures of two original samples individually detected by MCA

capillary gel electrophoresis (CE) and PAGE, Kummalue et al. [18] achieved $88.5 \%$ of sensitivity in 26 cases of B-cell non-Hodgkin lymphoma. Steiff et al. [20] found the similar sensitivity of MCA versus $\mathrm{CE}$ to detect clonal IgH rearrangement in 130 cases of gastric biopsy specimen. Furthermore, Uemura et al. [21] reported that PCR-MCA yielded $89.2 \%$ of sensitivity compared to southern blot analysis (42/45), while PAGE showed only $77.8 \%$ of sensitivity (35/45). All these reported studies targeting at CDR3 with FR3 primers showed no false positive results, resulting in consistent $100 \%$ of specificity.

In this study, we reinvestigate PCR with FR3 primers and MCA strategy using the newest modal of LightCycler. We have improved the analytical sensitivity from originally reported $12.5 \%$ [11] to current $3.125 \%$. We believed that the newer modal of LightCycler has a more precise temperature control system than the previous one. In addition, the reagents we used in this study are the optimal premix master that has minimized the PCRsuppression effect of SYBR Green I. All these may have contributed to a higher analytic sensitivity.

We also incorporate FR2 primers for the first time into the protocol. Combination of FR2 and FR3 primer sets enables us to detect 28 cases of (70.0 \% sensitivity) monoclonal IgH-R in 40 B-NHL FFPE samples, which detects $12.5 \%$ more cases than using FR3 primers alone. PCR-MCA with FR2 primers appears slightly more sensitive than PAGE (23 vs 21) and shows comparable sensitivity to CE (95.8 \%). The diagnostic sensitivity in this study was different from that reported by McClure et al. (60.8\%) [22], which detected 28 clonal IgH-R cases in 46 B-cell neoplasm FFPE samples using capillary gel electrophoresis with BIOMED-2 primers. We believe that the different lymphoma types and PCR reagents used in two studies may account for the discrepancy in detection rate. The Tm range of the $23 \mathrm{FR} 2$ positive cases was from $84{ }^{\circ} \mathrm{C}$ to $88{ }^{\circ} \mathrm{C}$ and the Tm range of FR3 cases we obtained was close to that reported by $\mathrm{Xu}$ et al. [11]. None of the 31 reactive lymphoid hyperplasia samples shows clonal peak, giving the specificity once again of $100 \%$.

\section{Conclusions}

In summary, to our knowledge, this is the first study combining FR2 and FR3 primers to determine IgH- $\mathrm{R}$ by melting curve analysis in LightCycler system, which is based on a fundamental DNA characteristic. Precise temperature control produces accurate and reproducible Tms. The results are reliable and promising with analytic as well as clinical sensitivities comparable with those of capillary gel electrophoresis. However, PCR-MCA in LightCycler has several advantages. This method can test 96 samples simultaneously within $90 \mathrm{~min}$. Therefore, it is high-throughput and faster. In addition, combined PCR and DNA melting curve analysis in a closed system reduces cross-contamination risk. Furthermore, it is more accessible than fragment analyzer for most hospitals in developing countries. Primers sets, such as FR1 of IGH or IGK may also be developed using MCA in the future to further improve overall sensitivity. We believe that PCRMCA in the Light Cycler system has potential for evaluating monoclonal IgH-R in a clinical environment.

\section{Abbreviations}

B-NHL: B-cell non-Hodgkin lymphoma; CDRs: Complementarity determining regions; CE: Capillary gel electrophoresis; $\mathrm{C} \mu$ : Immunoglobulin $\mathrm{M}$; FFPE: Formalin-fixed paraffin-embedded; FR2: Framework region 2; FR3: Framework region 3; Ig: Immunoglobulin; IgH: Immunoglobulin heavy chain; IgH-R: IgH rearrangement; MCA: Melting curve analysis;

PAGE: Polyacrylamide gel electrophoresis; Tm: Melting temperature.

\section{Competing interests}

The authors declare that they have no competing interests.

\section{Authors' contributions}

WC, ZY and DZ designed the study; WW, YG, QC and DX performed the study; DX' and DX' wrote the manuscript. All authors approved the final manuscript.

\section{Acknowledgements}

This work was supported by the National Natural Science Foundation of China (No. 30770907 and No. 81071418).

\section{Author details}

'Department of Clinical Laboratory, Peking Union Medical College Hospital, Peking Union Medical College, Chinese Academy of Medical Sciences, Beijing 100730, China. ${ }^{2}$ Hematopathology Program, CBL Path, Inc., Rye Brook, NY 10753, USA.

Received: 7 January 2015 Accepted: 27 July 2015

Published online: 09 August 2015

\section{References}

1. Skrabek $P$, Turner D, Seftel M. Epidemiology of non-Hodgkin lymphoma. Transfus Apher Sci. 2013;49(2):133-8. doi:10.1016/j.transci.2013.07.014

2. Chiu BC, Smith SM. Toward a global understanding of lymphoma: epidemiologic clues from the second most populous country. Leuk Lymphoma. 2013;54(5):901-2. doi:10.3109/10428194.2012.760042.

3. Ekstrom-Smedby K. Epidemiology and etiology of non-Hodgkin lymphoma-a review. Acta Oncol. 2006;45(3):258-71. doi:10.1080/02841860500531682.

4. Gazzola A, Mannu C, Rossi M, Laginestra MA, Sapienza MR, Fuligni F, et al. The evolution of clonality testing in the diagnosis and monitoring of hematological malignancies. Therapeutic Advances in Hematology. 2014:5(2):35-47. doi:10.1177/2040620713519729.

5. Tonegawa S. Somatic generation of antibody diversity. Nature. 1983;302(5909):575-81. 
6. van Dongen JJ, Langerak AW, Bruggemann M, Evans PA, Hummel M, Lavender FL, et al. Design and standardization of PCR primers and protocols for detection of clonal immunoglobulin and T-cell receptor gene recombinations in suspect lymphoproliferations: report of the BIOMED-2 Concerted Action BMH4-CT98-3936. Leukemia. 2003;17(12):2257-317. doi:10.1038/sj.leu.2403202.

7. Beaubier NT, Hart AP, Bartolo C, Willman CL, Viswanatha DS. Comparison of capillary electrophoresis and polyacrylamide gel electrophoresis for the evaluation of $\mathrm{T}$ and $\mathrm{B}$ cell clonality by polymerase chain reaction. Diagn Mol Pathol. 2000;9(3):121-31.

8. Brisco MJ, Tan LW, Orsborn AM, Morley AA. Development of a highly sensitive assay, based on the polymerase chain reaction, for rare B-lymphocyte clones in a polyclonal population. Br J Haematol. 1990;75(2):163-7.

9. Laszlo T, Kelenyi G, Matolcsy A. Clonality analysis of B-cell lymphoproliferative disorders by means of immunoglobulin heavy chain polymerase reaction. Orv Hetil. 1996;137(36):1963-7.

10. Tierens A, Lozano MD, Wickert R, Chan WC, Greiner TC. High-resolution analysis of immunoglobulin heavy-chain gene rearrangements using denaturing gradient gel electrophoresis. Diagn Mol Pathol. 1996;5(3):159-65.

11. Xu D, Du J, Schultz C, Ali A, Ratech H. Rapid and accurate detection of monoclonal immunoglobulin heavy chain gene rearrangement by DNA melting curve analysis in the LightCycler System. J Mol Diagn. 2002;4(4):216-22. doi:10.1016/s1525-1578(10)60706-4.

12. Langner KF, Joetzke AE, Nerschbach V, Eberle N, Schuberth HJ, Koy M, et al. Detection of clonal antigen receptor gene rearrangement in dogs with lymphoma by real-time polymerase chain reaction and melting curve analysis. BMC Vet Res. 2014;10:1. doi:10.1186/1746-6148-10-1.

13. Xu D, Du J, Kamino H, Ratech H. Rapid diagnosis of clonal immunoglobulin heavy chain gene rearrangements in cutaneous B-cell lymphomas using the LightCycler-Polymerase Chain Reaction with DNA melting curve analysis. Am J Dermatopathol. 2004;26(5):385-9.

14. Ke SH, Wartell RM. Influence of nearest neighbor sequence on the stability of base pair mismatches in long DNA; determination by temperature-gradient gel electrophoresis. Nucleic Acids Res. 1993;21(22):5137-43.

15. Ririe KM, Rasmussen RP, Wittwer CT. Product differentiation by analysis of DNA melting curves during the polymerase chain reaction. Anal Biochem. 1997;245(2):154-60. doi:10.1006/abio.1996.9916.

16. SantaLucia Jr J, Allawi HT, Seneviratne PA. Improved nearest-neighbor parameters for predicting DNA duplex stability. Biochemistry. 1996;35(11):3555-62. doi:10.1021/bi951907q.

17. Dobbs LJ, Earls L. Clonality analysis of B-cell lymphoproliferative disorders using PCR and melting curve analysis. Diagn Mol Pathol. 2003;12(4):212-23.

18. Kummalue T, Chuphrom A, Sukpanichanant S, Pongpruttipan T, Sukpanichanant S. Detection of monoclonal immunoglobulin heavy chain gene rearrangement (FR3) in Thai malignant lymphoma by High Resolution Melting curve analysis. Diagn Pathol. 2010;5:31. doi:10.1186/1746-1596-5-31.

19. Retamales E, Rodriguez L, Guzman L, Aguayo F, Palma M, Backhouse C, et al. Analytical detection of immunoglobulin heavy chain gene rearrangements in gastric lymphoid infiltrates by peak area analysis of the melting curve in the LightCycler System. J Mol Diagn. 2007;9(3):351-7. doi:10.2353/jmoldx.2007.050129.

20. Steiff JN, Neubauer A, Stolte M, Wundisch T. Clonality analyses in gastric MALT (mucosa-associated lymphoid tissue). Pathol Res Pract. 2006;202(7):503-7. doi:10.1016/j.prp.2006.02.006.

21. Uemura A, Mori S, Sugahara K, Akamatsu N, Tsuruda K, Tsukasaki K, et al. Rapid and high-resolution detection of IgH gene rearrangements using PCR and melting curve analysis. Int J Lab Hematol. 2007;29(3):200-7. doi:10.1111/j.1751-553X.2006.00832.x.

22. McClure RF, Kaur P, Pagel E, Ouillette PD, Holtegaard CE, Treptow CL, et al. Validation of immunoglobulin gene rearrangement detection by PCR using commercially available BIOMED-2 primers. Leukemia. 2006;20(1):176-9. doi:10.1038/sj.leu.2404049.

\section{Submit your next manuscript to BioMed Central and take full advantage of:}

- Convenient online submission

- Thorough peer review

- No space constraints or color figure charges

- Immediate publication on acceptance

- Inclusion in PubMed, CAS, Scopus and Google Scholar

- Research which is freely available for redistribution

Submit your manuscript at www.biomedcentral.com/submit 